\title{
Improved marker for the Rht-B1p dwarfing allele in wheat
}

\author{
M.S. Bazhenov ${ }^{1 *}$, L.A. Nazarova ${ }^{1}$, A.G. Chernook ${ }^{1,2}$, M.G. Divashuk ${ }^{1,2}$ \\ ${ }^{1}$ Laboratory of Applied Genomics and Crop Breeding, All-Russia Research Institute of Agricultural Biotechnology, Moscow, Russia \\ ${ }^{2}$ Centre for Molecular Biotechnology, Russian State Agrarian University - Moscow Timiryazev Agricultural Academy, Moscow, Russia
}

DOI 10.18699/ICG-PlantGen2019-61

(c) Autors, 2019

* e-mail: mikhabazhenov@gmail.com
Abstract: Introduction of dwarfing genes into wheat varieties is a way for improvement of lodging resistance and increasing grain yield. Recently, the Rht-B1p allele (formerly designated as 'Rht17') associated with reduced plant height has been sequenced. However, the PCR markers developed previously for its detection were not perfect, and sometimes gave confusing results. In this work, we designed new primers for detection of the Rht-B1p allele and optimized PCR conditions for them. The new PCR marker can confidently detect the Rht-B1p allele in common wheat.

Key words: plant height; wheat; molecular markers; PCR; Rht17; Rht-B1p.

\section{Introduction}

Introduction of dwarfing genes into cereal crop varieties was crucial for increasing food production in the last 40 years of the XX century (Hedden, 2003). Irrigation and application of higher doses of fertilizers mainly increase yield. However, in the case of tall wheat varieties, these practices cause lodging, leading to heavy economic losses. Semi-dwarf wheat plants possessing shorter and stronger stalks are more resistant to lodging. Semi-dwarf wheat varieties make it possible to obtain higher yields under conditions of intensive agriculture.

The semi-dwarf plant height of contemporary wheat was achieved mainly due to the gibberellin-insensitive dwarfing genes Rht1 (the modern designation "Rht-Blb") and Rht2 ("Rht-Dlb"), which were introduced into American and European varieties from the Japanese variety 'Norin 10' (Borojevic, Borojevic, 2005). The advantage of the gibberellin-insensitive dwarfing genes is that they not only increase resistance to lodging, but also have a positive effect on the partitioning of the assimilates towards the developing ear, thereby further increasing grain yield. However, these genes have some disadvantages, for example, increased susceptibility to Fusarium head blight and shortening of the coleoptile of the seedlings, leading to a decrease in germination rate under conditions of deep sowing (Srinivasachary et al., 2008; Grover et al., 2018).

In addition to Rht-B1b and Rht-D1b, there are several other alleles of these genes that cause plant height reduction. At the same time, it is known that different alleles, despite the same molecular mechanism of their action, can affect the height and other economically valuable traits to slightly varying degrees. This can be caused by differences in their overall level of expression, and in expression patterns in different plant tissues. For example, it is known that the $R h t-D 1 b$ allele has a greater effect on susceptibility to Fusarium head blight than Rht-B1b (Srinivasachary et al., 2008), and the allele Rht-Ble (previously referred to as "Rht11") reduces plant height slightly stronger than Rht-B1b (Divashuk et al., 2012).

The effect of the Rht-B1p allele (previously designated as "Rht17") on the economically valuable traits of wheat has not yet been studied as sufficiently as those of other reducedheight alleles (Bazhenov et al., 2015). In this regard, reliable molecular markers for its identification are required. The dominant markers previously developed by us for identifica- tion of Rht-B1p in some cases give difficult-to-interpret results. Thus, we re-developed the primers and optimized the PCR conditions for reliable identification of the Rht-B1p allele (or its lack) in common wheat.

\section{Materials and Methods}

The following common wheat accessions with known reduced-height genes were used as a plant material: 'Novosibirskaya 67' (Rht-B1a), PI518620 (Rht-B1b), 'Karlik-1' (Rht-B1e), and 'Chris Mutant' (Rht-B1p). F3 lines of the 'Chris Mutant'/'Novosibirskaya 67' intercross were used for validation of the markers.

DNA samples were isolated from seedlings using the CTAB protocol (Doyle, 1991).

Primers for detection of the Rht-BIp allele were designed based on the known sequence (GenBank: KT013263.1) for combined use with the BF primer: 5'GGTAGGGAGG CGAGAGGCGAG3' (Ellis et al., 2002). The primer length was chosen based on its calculated melting temperature. The melting temperatures of the primers were calculated according to the method of Santa Lucia (Santa Lucia, 1998) using Primer-BLAST (NCBI).

For detection of the Rht-B1p allele, we designed the RhtB1p-R primer: 5'-CCATCTCCAGCTGCTCCAGCTTATA-3', and for detection of any of the other alleles, the Rht-B1a-R primer: 5'-CCATCTCCAGCTGCTCCAGCTTATG-3'. To enhance annealing specificity, we incorporated noncomplementary nucleotides (underlined) near the $3^{\prime}$ ends of the primers. The positions of the primers on the sequence of the gene are shown in Figure 1.

The PCR was performed using a GeneAmp PCR System 9700 (Applied Biosystems) in $25-\mu \mathrm{L}$ reaction volumes containing $70 \mathrm{mM}$ Tris- $\mathrm{HCl}$ buffer ( $\mathrm{pH} 8.6$ ), $16.6 \mathrm{mM}$ $\left(\mathrm{NH}_{4}\right)_{2} \mathrm{SO}_{4}, 2.5$ or $1.5 \mathrm{mM} \mathrm{MgCl}, 0.2 \mathrm{mM}$ of each dNTP, $0.3 \mu \mathrm{M}$ of forward and reverse primers, $1.25 \mathrm{U}$ of Taq-polymerase (Sileks), and $100 \mathrm{ng}$ of template DNA.

During optimization of the PCR conditions, we tested two concentrations of $\mathrm{MgCl}_{2}(2.5$ and $1.5 \mathrm{mM})$, and a range of annealing temperatures, $56-64{ }^{\circ} \mathrm{C}$, in the main cycle.

The optimized PCR conditions were as follows: (1) $95^{\circ} \mathrm{C}$ for 10 minutes; (2) 5 cycles at $94{ }^{\circ} \mathrm{C}$ for 30 seconds, $67^{\circ} \mathrm{C}$ with a $1{ }^{\circ} \mathrm{C}$ drop every next cycle for $60 \mathrm{~s}, 72{ }^{\circ} \mathrm{C}$ for $80 \mathrm{~s}$; 


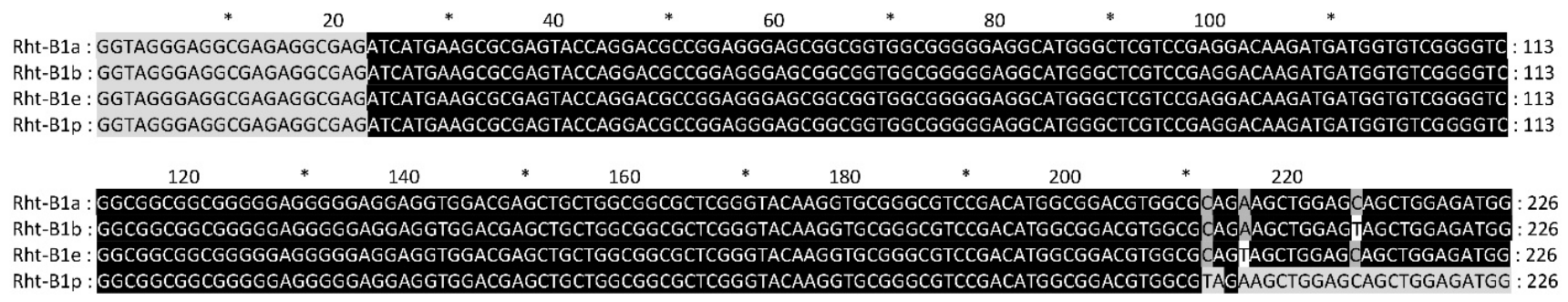

Figure 1. Alignment of the different Rht-B1 alleles $(a, b, e, p)$ and the positions of the primers BF and RhtB1pR (highlighted).

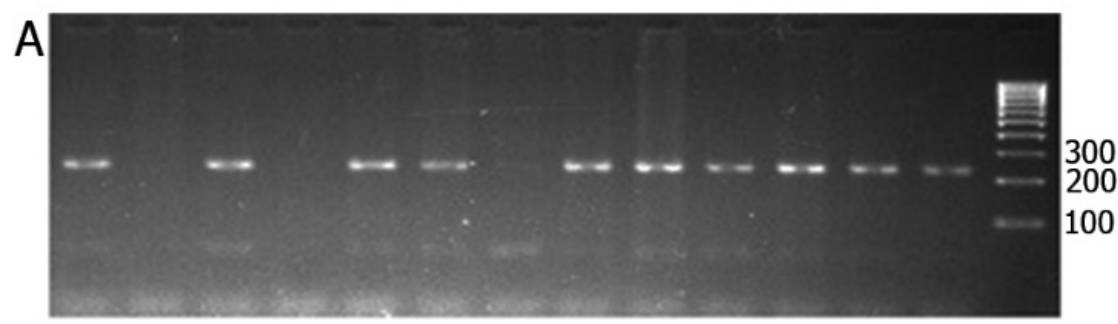

B

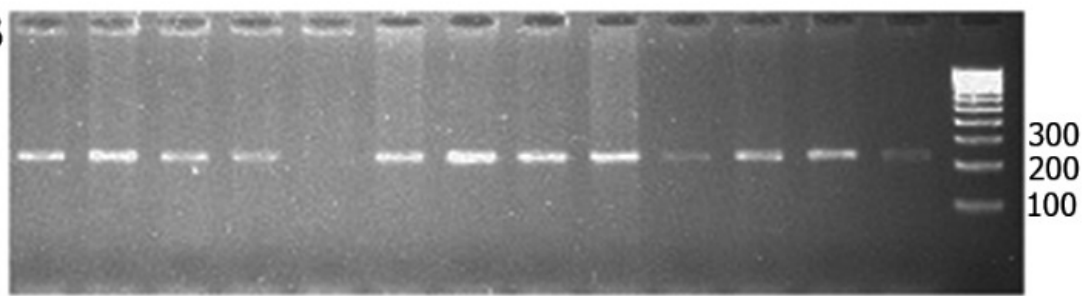

Figure 2. An example of the electrophoresis of the $P C R$ products obtained using the primers (A) BF/RhtB1pR and (B) BF/Rht-B1a-R and the DNA of the $F_{3}$ plants of the 'Chris Mutant'/'Novosibirskaya 67 ' intercross. The PCR product length is 226 base pairs. Plant 5 is a homozygote for Rht-B1p; plants 2, 4, and 7 are homozygotes for Rht-B1a; other plants are heterozygotes. M, DNA size standard M-100 (JSC Synthol).
(3) 30 cycles at $94{ }^{\circ} \mathrm{C}$ for 30 seconds, $62^{\circ} \mathrm{C}$ for $30 \mathrm{~s}, 72^{\circ} \mathrm{C}$ for $50 \mathrm{~s}$; (4) $72{ }^{\circ} \mathrm{C}$ for $10 \mathrm{~min}$.

The PCR products were subjected to electrophoresis in a $1.5 \%$ agarose gel run with TBE buffer with the addition of ethidium bromide. The gels were visualized using a Gel Doc $\mathrm{XR}+$ gel imaging system (Bio-Rad).

\section{Results and Discussion}

Introduction of 5 touchdown cycles at the beginning of the PCR allowed us, on the one hand, to enhance the specificity of the annealing of the primers and, on the other hand, to increase the amount of the resulting PCR product. As our experiments showed, further amplification could be conducted at a broad range of temperatures $\left(56\right.$ to $\left.63^{\circ} \mathrm{C}\right)$. We established the optimal annealing temperature in the main PCR cycles to be $62{ }^{\circ} \mathrm{C}$ for both primer pairs.

Separately, the markers obtained using each primer pair are dominant. However, the PCRs conducted with both primer pairs in combination can easily distinguish between the homozygous and heterozygous genotypes of the plants in the crosses of wheat accessions with the Rht-Bla and Rht-Blp alleles (Figure 2).

Compared to our previous primers for detection of $R h t-B 1 p$ (Bazhenov et al., 2015), our new ones being used under optimal conditions do not give any byproducts that can confuse the researcher. Testing our new primers on accessions with different $R h t-B 1$ alleles showed that the BF/Rht-B1p-R primer pair is perfectly specific for the Rht-B1p allele. However, the $\mathrm{BF} / \mathrm{Rht}-\mathrm{B}$ la-R primer pair gives only a faint PCR-product when the $R h t-B 1 b$ allele is present. Thus, in cannot perfectly detect the absence of the $R h t-B 1 p$ allele, if $R h t-B 1 b$ is present. To analyze the genotypes of the plants in the populations that segregate for $R h t-B 1 p$ and $R h t-B 1 b$ alleles, we recommend to use the $\mathrm{BF} / \mathrm{Rht}-\mathrm{B} 1 \mathrm{p}-\mathrm{R}$ primer pair for the $R h t-B 1 p$ allele, and the BF/MR1 primer pair proposed for detection of $R h t-B 1 b$ by Ellis et al. (2002).

\section{Conclusions}

Our new PCR markers, used under optimized conditions, can confidently detect the Rht-B1p allele in common wheat and discriminate its homozygous and heterozygous genotypes. Application of these markers will facilitate introduction of the $R h t-B 1 p$ dwarfing allele to new wheat varieties.

\section{References}

Bazhenov M.S., Divashuk M.G., Amagai Y., Watanabe N., Karlov G.I. Isolation of the dwarfing Rht-B1p (Rht17) gene from wheat and the development of an allele-specific PCR marker. Mol. Breed. 2015; 35(11). DOI 10.1007/s11032-015-0407-1.

Borojevic K., Borojevic K. The transfer and history of «reduced height genes» (Rht) in wheat from Japan to Europe. J. Hered. 2005;96(4): 455-459. DOI 10.1093/jhered/esi060.

Divashuk M.G., Vasilyev A.V., Bespalova L.A., Karlov G.I. Identity of the Rht-11 and Rht-B1e reduced plant height genes. Russ. J. Genet. 2012;48(7):761-763. DOI 10.1134/S1022795412050055. 
Doyle P.J. DNA Protocols for Plants. Molecular Techniques Taxonomy. 1991;57(1):283-293. DOI 10.1007/978-3-642-83962-7.

Ellis M., Spielmeyer W., Gale K., Rebetzke G., Richards R. «Perfect» markers for the Rht-B1b and Rht-D $1 \mathrm{~b}$ dwarfing genes in wheat. Theor. Appl. Genet. 2002;105(6-7):1038-1042. DOI 10.1007/s00122002-1048-4.

Grover G., Sharma A., Gill H.S., Srivastava P., Bains N.S. Rht8 gene as an alternate dwarfing gene in elite Indian spring wheat cultivars. PLOS ONE. 2018;13(6):e0199330. DOI 10.1371/journal.pone. 0199330.

Hedden P. The genes of the Green Revolution. Trends Genet. 2003; 19(1):5-9. DOI 10.1016/S0168-9525(02)00009-4.
SantaLucia J. A unified view of polymer, dumbbell, and oligonucleotide DNA nearest-neighbor thermodynamics. Proc. Natl. Acad. Sci. 1998;95(4):1460-1465. DOI 10.1073/pnas.95.4.1460.

Srinivasachary, Gosman N., Steed A., Hollins T.W., Bayles R., Jennings P., Nicholson P. Semi-dwarfing Rht-B1 and Rht-D1 loci of wheat differ significantly in their influence on resistance to Fusarium head blight. Theor. Appl. Genet. 2008;118(4):695-702. DOI 10.1007/s00122-008-0930-0.

Acknowledgements. This research was funded by Russian Science Foundation, grant number 17-76-20023.

Conflict of interest. The authors declare no conflict of interest. 